Nonlinear analysis of crack widths in reinforced concrete

$\mathrm{K}$. Tammo, K. Lundgren and S. Thelandersson

Published in Magazine of Concrete Research, see journal homepage http://www.icevirtuallibrary.com/content/journals

"Permission is granted by ICE Publishing to print one copy for personal use. Any other use of these PDF files is subject to reprint fees." 


\title{
Nonlinear analysis of crack widths in reinforced concrete
}

\author{
K. Tammo*, K. Lundgren† and S. Thelandersson* \\ Lund Institute of Technology; Chalmers University of Technology
}

\begin{abstract}
Former research indicates that the crack width close to the bar can be a better indicator for the risk for reinforcement corrosion than, as current concrete codes impose, the crack width at the concrete surface. In this paper a finiteelement model is used to increase the understanding of how the crack width varies at different levels from the reinforcement and how different mechanisms control this behaviour. Concrete and reinforcement are modelled with solid elements, where nonlinear fracture mechanics is used for the concrete material and a model, which has been modified for this purpose, describes the bond between steel and concrete. The results of the finite-element calculations of the crack widths are compared to earlier experimental studies. Both the finite-element analysis and experimental studies are performed on axially loaded concrete prisms with a central $16 \mathrm{~mm}$ reinforcement bar and concrete covers of 30,50 and $70 \mathrm{~mm}$. The finite-element analysis verifies the results from former experimental research, where the crack widths close to the reinforcement bar are affected only slightly, or not at all, by the concrete cover. This can lead to new possibilities of enlarging the concrete cover and increasing the durability of concrete structures in future.
\end{abstract}

\section{Introduction}

In cracked concrete the reinforcement is exposed to free oxygen and moisture, which can cause corrosion. It is therefore important to minimise the exposed bar length. Methods for crack control currently focus on the limitation of surface cracks. With respect to risk for corrosion, the crack width in the vicinity of the reinforcement bars is more relevant. Several researchers have investigated the variation of crack width from the bar level to the surface by measuring the displacements of a concrete end surface with a bar embedded in it. ${ }^{1-6}$ It was found that surface crack widths are of the order of at least twice the crack width close to the bar surface for normal thicknesses of the concrete cover.

According to Tammo and Thelandersson ${ }^{2}$ the difference between surface crack width and the crack width close to the bar is explained by the behaviour of the concrete in the bond zone adjacent to cracks. Small

* Division of Structural Engineering, Lund Institute of Technology, P.O. Box 118, SE-221 00, Lund, Sweden

$\dagger$ Division of Structural Engineering, Chalmers University of Technology, SE-412 96, Göteburg, Sweden

(MACR-D-08-00048) Paper received 4 March 2008; last revised 18 June 2008; accepted 22 August 2008 inclined cracks develop at the bar interface at higher steel stresses, as illustrated in Fig. 1(a), and bond is gradually weakened so that the displacement of the bar relative to the displacement of the outer concrete increases. The displacement relative to the concrete close to the bar is, however, much lower because of the small diagonal cracks. This occurs because the concrete near the bar is separated from the rest of the concrete and more or less follows the bar when it is pulled out at high steel stresses. The cracked zone was also coloured with phenolphthalein, as shown in Fig. 1(b), making the inclined cracking pattern clearly visible.

The results from previous research indicate that more efforts are needed to understand the mechanisms and variables governing the crack width at the bar. The results from Tammo and Thelandersson ${ }^{1,2}$ show that crack width at the bar is not influenced by various parameters in the same way as surface crack width. For instance, surface crack widths depend to some extent on the thickness of concrete cover, but the influence on crack width at the bar level is very small.

In the present paper, the mechanism of cracking behaviour will be evaluated with axisymmetric, nonlinear finite-element calculations. The formation of the two faces in a crack will be simulated and compared with the measured values from Tammo and Thelandersson. ${ }^{1,2}$ The simulation of the separated 


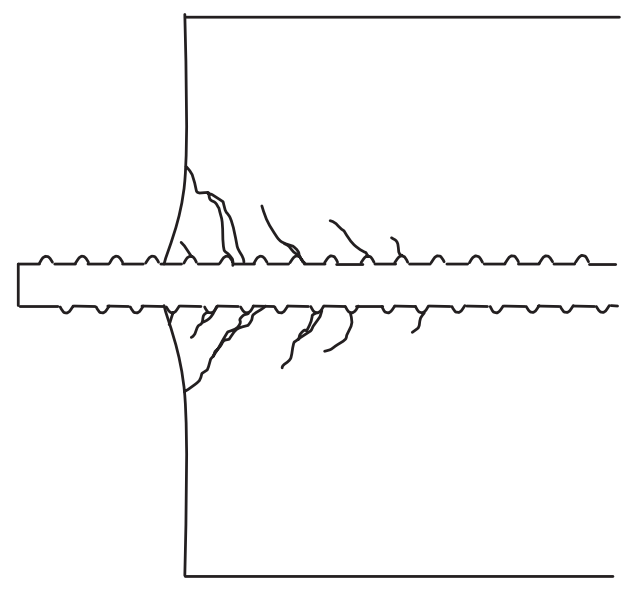

(a)

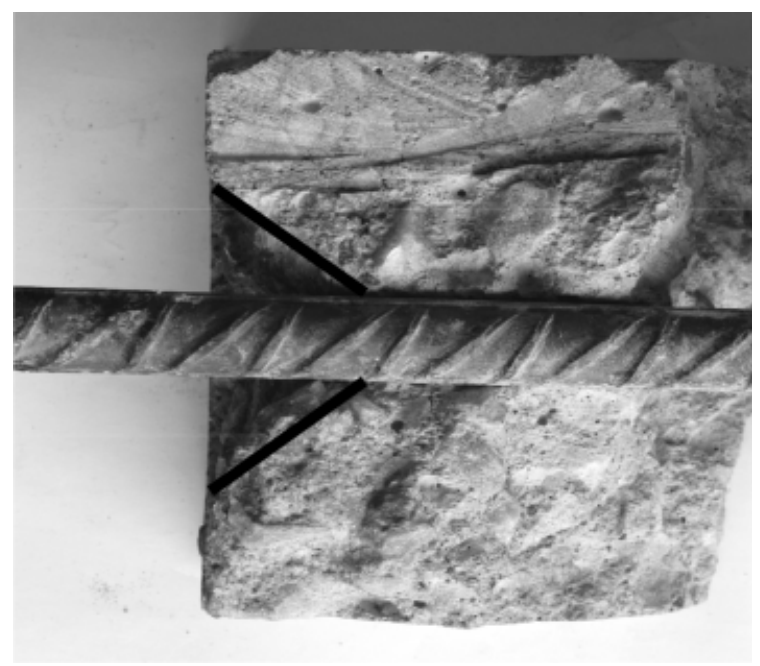

(b)

Fig. 1(a) The concrete near the bar is separated from the rest of the concrete and small inclined cracks develop at the bar interface. (b) By colouring the cracked zone the spread of the inclined cracks is visible

concrete near the bar is of special importance, as it is one of the main factors that cause the non-uniform crack face. The results presented in this paper will also be used to evaluate the validity of some present crack codes.

\section{Materials and experimental methods}

In the experimental tests carried out by Tammo and Thelandersson ${ }^{1,2}$ axially loaded concrete prisms with a central $16 \mathrm{~mm}$ reinforcement bar are tested, see Fig. 2(a). Three different concrete covers - 30, 50 and $70 \mathrm{~mm}$ - are used so that the quadratic cross-sections of the specimens become 76,116 and $156 \mathrm{~mm}$ respectively. The length of the specimens is $500 \mathrm{~mm}$ for the specimens with concrete covers 30 and $50 \mathrm{~mm}$. For the specimen with $70 \mathrm{~mm}$ concrete cover a length of $1000 \mathrm{~mm}$ is used for all cases but one, where a length of $500 \mathrm{~mm}$ is used. ${ }^{2}$ Tension is applied in the reinforcement bar under displacement control $(0.42 \mathrm{~mm} / \mathrm{min})$,

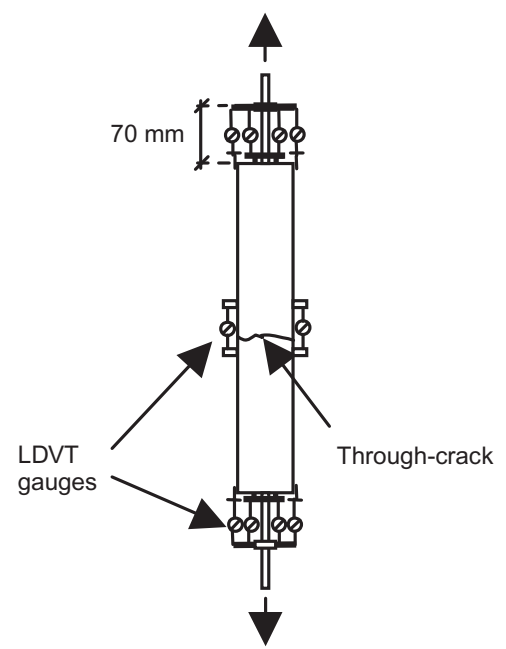

(a)

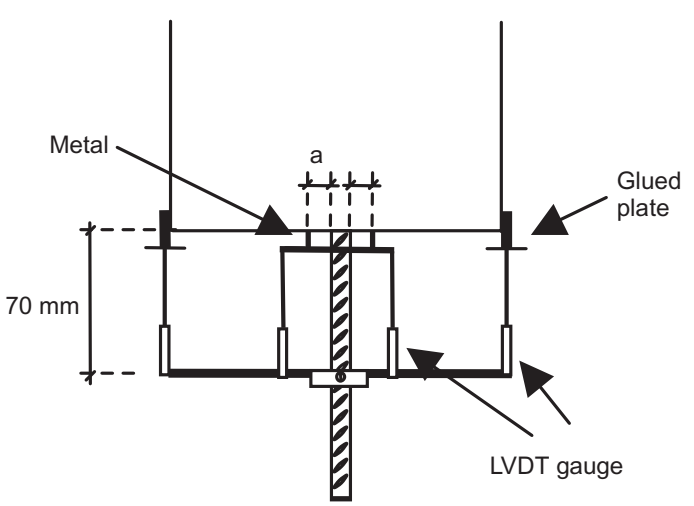

(b)

Fig. 2(a) Axially loaded concrete prisms from the experimental study of Tammo and Thelandersson; ${ }^{1,2}$ (b) measuring device for estimation of the crack width at different distances from the reinforcement bar

and the slip of the bar relative to the concrete end surface is measured, see Fig. 2(a). The concrete specimens are loaded until the steel stress reaches $400 \mathrm{MPa}$. The reference points for slip measurements at the concrete end surface are located at a distance $a(\mathrm{~mm})$ from the nominal surface of the ribbed bar, which is $8 \mathrm{~mm}$ from the central axis of the bar, see Fig. 2(b). Two different values of $a-4.5$ and $11 \mathrm{~mm}$ - are used in the tests.

The reinforcement is of quality B500B with characteristic yield strength $500 \mathrm{MPa}$ and the concrete has an average 28-day compressive strength of $64.81 \mathrm{MPa}$ (150 mm cubes).

The slip of the bar is measured with linear variable differential transducer (LVDT) gauges (accuracy of $0.001 \mathrm{~mm}$ ) as the relative displacement between a metal tube resting on the concrete surface and a point on the bar $70 \mathrm{~mm}$ from the concrete end surface, see Fig. 2(b). The metal tubes have knife edges in contact with the concrete end surface, so that the position $a$ is determined with high precision. The reading is corrected for the elongation of the bar on the $70 \mathrm{~mm}$

Magazine of Concrete Research, 2009, 61, No. 1 
length, based on the applied load and the value of the axial stiffness, $E A$, for the bars. The measured slip is interpreted as half the crack width at distance $a$ from the bar surface. The crack width $4.5 \mathrm{~mm}$ and $11 \mathrm{~mm}$ from the reinforcement bar is therefore calculated as twice the measured slip.

To estimate the crack width at the concrete surface additional LVDTs are mounted to measure the slip relative to a plate glued on the longitudinal surface of the prisms at the ends of the specimens, see Fig. 2(b). The readings from these gauges are used in a similar way to determine crack width at the concrete surface.

\section{Finite-element model}

To increase the understanding of the crack mechanisms a finite-element model is used. The analyses are carried out in the finite-element program Diana. Concrete and reinforcement are modelled with solid elements and the connection between concrete and reinforcement is modelled with special interface elements. A linear elastic model is used to describe the steel reinforcement. For the concrete material nonlinear fracture mechanics is used, with a rotating crack model based on total strain. ${ }^{7}$ Axisymmetric models are used, assuming four radial cracks. In compression, the hardening-softening curve according to Thorenfeldt ${ }^{8}$ is used, and the curve by Hordijk et al. ${ }^{9,10}$ is chosen for the tension softening of concrete, as described by the Netherlands Organisation for Applied Scientific Research (TNO). ${ }^{7}$

A model by Lundgren ${ }^{11}$ describes the bond between steel and concrete. The interface elements describe the relation between traction $t$ and the relative displacement $u$ in the interface and have, initially, a thickness of zero. The variables in these interface elements are $t_{\mathrm{n}}, t_{\mathrm{t}}, u_{\mathrm{n}}$ and $u_{\mathrm{t}}$, see Fig. 3 .

The model for the interface is a frictional one based on elasto-plastic theory and describes the relations between stresses and displacements. In the elastic range, the equations for this model are

$$
t=\left[\begin{array}{c}
t_{\mathrm{n}} \\
t_{\mathrm{t}}
\end{array}\right]=\left[\begin{array}{cc}
D_{11} & 0 \\
0 & D_{22}
\end{array}\right]\left[\begin{array}{l}
u_{\mathrm{n}} \\
u_{\mathrm{t}}
\end{array}\right]
$$

The elastic stiffness $D_{11}$ is equal as in Lundgren ${ }^{11}$ and changes with the displacement $u_{\mathrm{n}}$. To avoid numerical problems a maximum value of $D_{11}$ is chosen for nega-

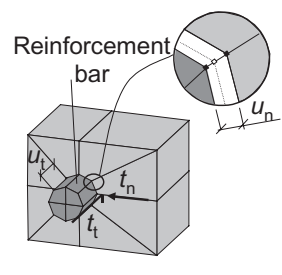

$$
\begin{aligned}
& t_{\mathrm{n}}=\text { normal stress } \\
& t_{\mathrm{t}}=\text { bond stress } \\
& u_{\mathrm{t}}=\text { slip } \\
& u_{\mathrm{n}}=\text { relative normal displacement in the } \\
& \quad \text { layer }
\end{aligned}
$$

Fig. 3. The connection between concrete and reinforcement is modelled with special interface elements. From Lundgren ${ }^{11}$

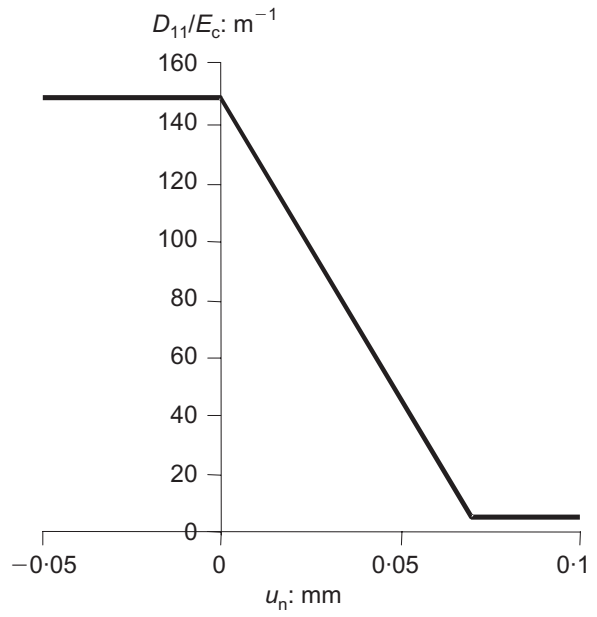

Fig. 4. The stiffness $D_{11}$; from Lundgren ${ }^{11}$

tive $u_{\mathrm{n}}$ and a minimum value for positive $u_{\mathrm{n}}$, as shown in Fig. 4.

The elastic stiffness $D_{22}$ is chosen to be equal as in Lundgren $^{8}$ and is

$$
D_{22}=K_{22} E_{\mathrm{c}}
$$

where $K_{22}=6.0 \mathrm{~m}^{-1}$ and $E_{\mathrm{c}}$ is the elastic modulus of the concrete.

The yield line describing friction, $F_{1}$, is written as

$$
F_{1}=\left|t_{\mathrm{t}}\right|+\mu\left(t_{\mathrm{n}}-f_{\mathrm{a}}\right)=0
$$

where $\mu$ is the coefficient of friction and is assumed to be a function of the hardening parameter $\kappa$, which is $\mu(\kappa)$ as shown in Fig. 5(a); and $f_{\mathrm{a}}$ is the adhesion and is considered to vary with the hardening parameter $\kappa$ as $f_{\mathrm{a}}(\kappa)$, as shown in Fig. 5(b).

In Lundgren ${ }^{11}$ large steel stresses are of special interest and the effect of adhesion $f_{\mathrm{a}}$ is therefore neglected. In this investigation even small steel stresses are of importance and the adhesion is therefore included in the model.

The hardening parameter $\kappa$ is defined by

$$
\mathrm{d} \kappa=\sqrt{\mathrm{d} u_{\mathrm{n}}^{p 2}+\mathrm{d} u_{\mathrm{t}}^{p 2}}
$$

and describes the hardening rule of the model. As the loading is monotonic both $\mathrm{d} u_{\mathrm{n}}^{p}$ and the elastic part of the slip are very small compared to the plastic part of the slip, $\mathrm{d} u_{\mathrm{t}}^{p}$, and the hardening parameter $\kappa$ will be almost equivalent to the slip, $u_{\mathrm{t}}$.

For the yield line describing the friction, $F_{1}$, a nonassociated flow rule is equal as in Lundgren, ${ }^{11}$ where the plastic part of the displacement, $\mathrm{d} u_{\mathrm{p}}$, is described by

$$
\mathrm{d} u^{p}=d \lambda \frac{\partial G}{\partial t}, \quad G=\frac{\left|u_{\mathrm{t}}\right|}{u_{\mathrm{t}}} t_{\mathrm{t}}+\eta t_{\mathrm{n}}=0
$$

where $\mathrm{d} \lambda$ is the incremental plastic multiplier and $\eta$ is the dilation parameter.

The parameter $\eta$ shall be chosen in order to obtain a decreasing bond stress when the concrete around the 


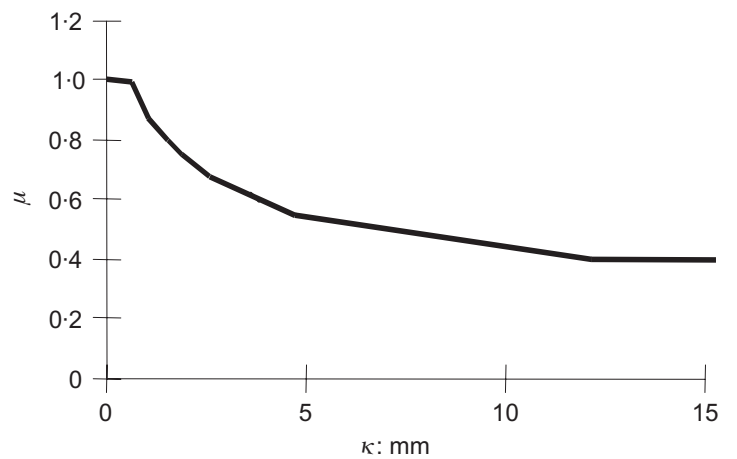

(a)

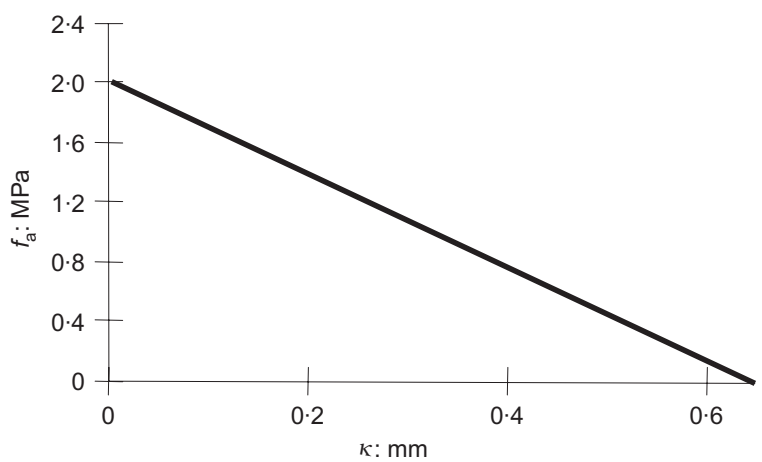

(b)

Fig. 5(a). Chosen input for: (a) the coefficient of friction as a function of the hardening parameter; (b) the adhesion as a function of the hardening parameter

bar splits, without elastic unloading. Through calibration in Lundgren, ${ }^{11} \eta$ is chosen to be $0 \cdot 04$.

Input parameters for the materials in the finiteelement program are evaluated from cube strength and steel quality and are presented in Table 1 .

As the results from the finite-element calculations will be compared with measured values from Tammo and Thelandersson ${ }^{1,2}$ the geometries should be similar. To simplify the calculations, however, the geometry is approximated as a cylinder by using an axisymmetric model. The diameter of the circular cross-section is equal to the sides of the square cross-section, as shown in Fig. 6 and the concrete covers $c$ are therefore 30, 50 and $70 \mathrm{~mm}$. The length of the cylinder is $500 \mathrm{~mm}$ for all types of specimens - that is, also for the concrete cover of $70 \mathrm{~mm}$. By use of symmetry only half of the specimen $(250 \mathrm{~mm})$ is represented in the finite-element model, as shown in Fig. 7.

Table 1. Material parameters

\begin{tabular}{l|c|c}
\hline Material parameter & Concrete & Steel \\
\hline Compressive strength, $f_{\mathrm{c}}: \mathrm{MPa}$ & 55 & - \\
Tensile strength, $f_{\mathrm{t}}: \mathrm{MPa}$ & $3 \cdot 91$ & - \\
Yield strength: $\mathrm{MPa}$ & - & 568 \\
Modulus of elasticity, $E: \mathrm{MPa}$ & 38000 & 200000 \\
Poisson's ratio, $v$ & $0 \cdot 15$ & $0 \cdot 3$ \\
Fracture energy: N/m & $98 \cdot 9$ & - \\
\hline
\end{tabular}
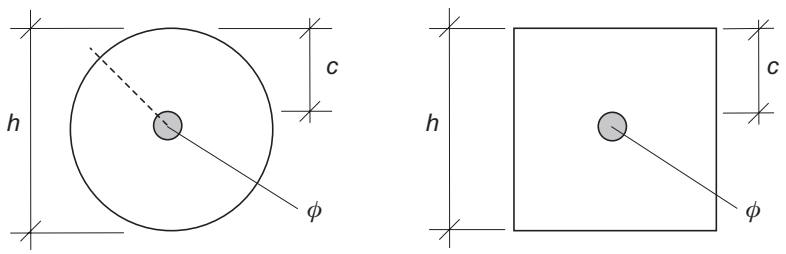

Fig. 6. The quadratic cross-section of the test specimens is simplified to a circular cross-section in the finite-element model; $\phi$ is the diameter of the bar, $h$ is the external dimension and $c$ is concrete cover

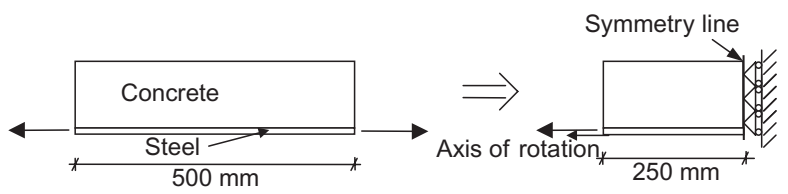

Fig. 7. Because of the symmetric effects the length of the specimen is halved in the model

The method of defining the crack width, which is interpreted as twice the slip, is similar in the finiteelement model as for the real test specimens. The distance $a$ from the bar surface is in this case 5 and $10 \mathrm{~mm}$ instead of 4.5 and $11 \mathrm{~mm}$ to comply with the finite-element method (FEM)-grid.

\section{Analysis of calculated results}

\section{Comparison of crack widths}

The results for the crack widths from the finiteelement analysis (FEA) at different distances from the bar surface are compared with the measured crack widths in Figs 8, 9 and 10. The measured crack widths are evaluated from regression lines, see Tammo and Thelandersson. ${ }^{1,2}$ The $R^{2}$-values for these regression curves are in all cases over $0 \cdot 6$, which is acceptable as a lower limit for reliable results.

Multiple cracking in the specimen can cause unstable calculations. The reliability of each analysis was checked as follows. The default values for the displacement, energy and force norms to check convergence recommended by $\mathrm{TNO}^{7}$ were used. If these were not reached after a certain number of iterations, the analyses were continued regardless. The results of the calculations thereafter were considered to be reliable as long as the norms were not exceeded by more than 10 times the original limit values. The calculations for the test specimen with $30 \mathrm{~mm}$ concrete cover are considered as reliable until the steel stress is $150 \mathrm{MPa}$, for specimen with $50 \mathrm{~mm}$ concrete cover until the steel stress is $400 \mathrm{MPa}$ and for the specimen with $70 \mathrm{~mm}$ concrete cover until the steel stress is $300 \mathrm{MPa}$.

The results of the test specimen with $30 \mathrm{~mm}$ concrete cover are not analysed in detail since the analysis becomes unstable for steel stresses over $150 \mathrm{MPa}$.

In a qualitative sense the results of the calculations 


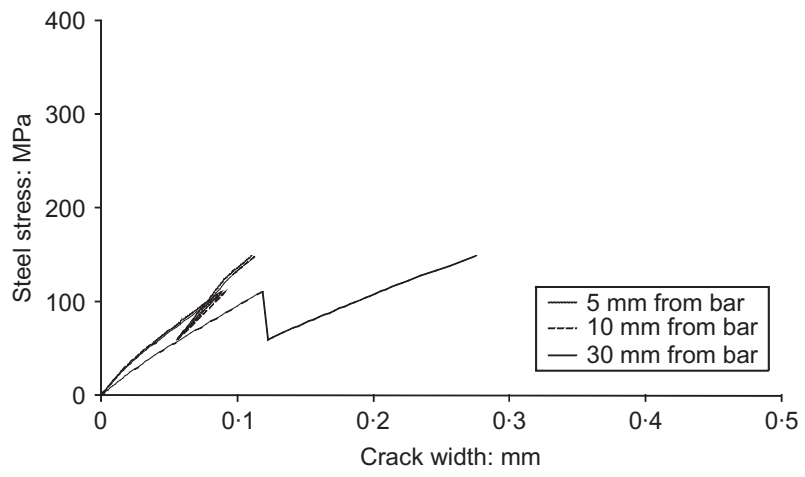

(a)

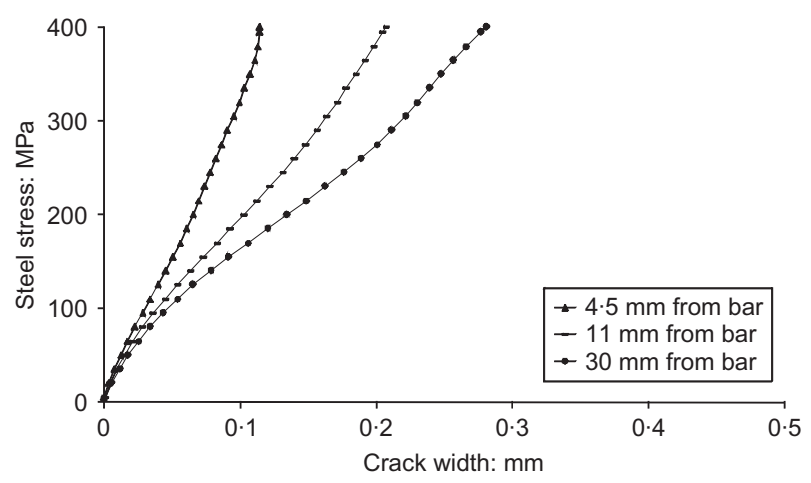

(b)

Fig. 8(a). Calculated crack widths $5 \mathrm{~mm}, 10 \mathrm{~mm}$ and $30 \mathrm{~mm}$ from the reinforcement bar for specimens with $30 \mathrm{~mm}$ concrete cover; (b) crack widths measured $4.5 \mathrm{~mm}, 11 \mathrm{~mm}$ and $30 \mathrm{~mm}$ from the reinforcement bar at specimens with $30 \mathrm{~mm}$ concrete cover

agree with the experimental results from Tammo and Thelandersson ${ }^{1,2}$ where the crack width close to the reinforcement bar was found to be almost unaffected by the size of the concrete cover. As an example: if the steel stress is $300 \mathrm{MPa}$ the calculated crack width $10 \mathrm{~mm}$ from the bar surface is $0.204 \mathrm{~mm}$ and $0.291 \mathrm{~mm}$ at the concrete surface for the specimen with $50 \mathrm{~mm}$ concrete cover. For the specimen with $70 \mathrm{~mm}$ concrete cover the corresponding crack widths are $0.201 \mathrm{~mm}$ and $0.344 \mathrm{~mm}$. Thus the calculated crack width close to the bar is similar for both specimens; the difference in crack width at the concrete surface is $0.040 \mathrm{~mm}$.

The development of the calculated crack widths is similar for the specimens with $50 \mathrm{~mm}$ and $70 \mathrm{~mm}$ concrete cover. The calculated crack widths at the concrete surface for these specimens agree reasonably well with the measured values. For both calculations and experiments the crack width at the concrete surface increases significantly for large steel stresses, while the crack widths close to the bar only grow to a limited extent with steel stress.

The calculated crack widths close to the bar make a sudden drop of about $0.015 \mathrm{~mm}$ at a specific steel stress for both specimens with $50 \mathrm{~mm}$ and $70 \mathrm{~mm}$ concrete cover. For the specimen with $50 \mathrm{~mm}$ concrete cover this happens at a steel stress of $300 \mathrm{MPa}$ and for

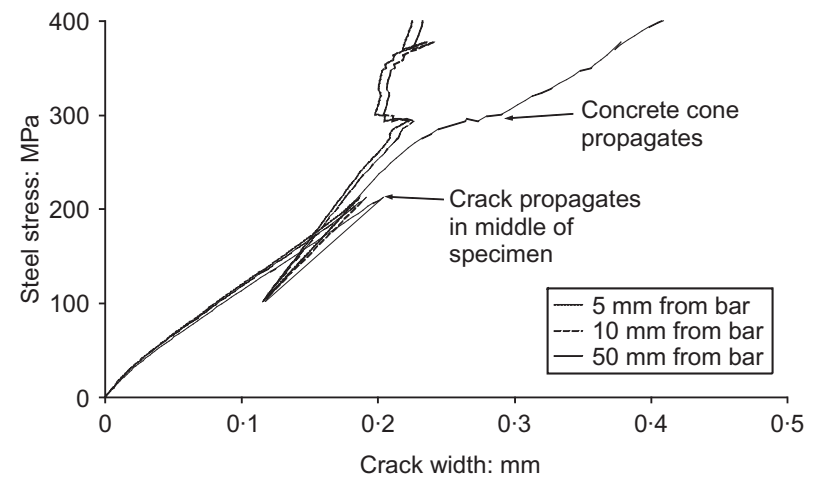

(a)

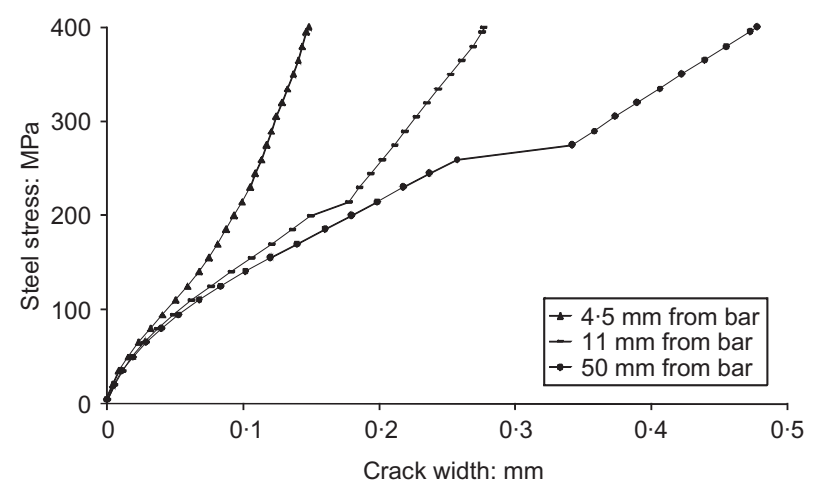

(b)

Fig. 9(a). Calculated crack widths $5 \mathrm{~mm}, 10 \mathrm{~mm}$ and $50 \mathrm{~mm}$ from the reinforcement bar for specimens with $50 \mathrm{~mm}$ concrete cover; (b) crack widths measured $4.5 \mathrm{~mm}, 11 \mathrm{~mm}$ and $50 \mathrm{~mm}$ from the reinforcement bar at specimens with $50 \mathrm{~mm}$ concrete cover

the specimen with $70 \mathrm{~mm}$ concrete cover at the steel stress of $230 \mathrm{MPa}$, see Figs 9(a) and 10(a). The explanation for this quite sudden reduction of crack widths close to the bar is that concrete near the bar at the end of the specimen is separated from the rest of the concrete and follows the bar, as shown in Fig. 1. The coneshaped geometry of this concrete piece is also visible in the finite-element meshes.

The calculated crack widths close to the bar are for low steel stresses larger than the measured crack widths; compare Fig. 9 and Fig. 10. Even the sudden reduction of the crack widths close to the bar when the cone is created is not observed in the experiments. In contrast to the calculated crack widths, the difference between measured crack widths close to the reinforcement bar and at the concrete surface is observed even at low steel stresses and increases with stress. These differences indicate that the nonlinear damage processes of the bond zone near the crack cannot be captured in detail by the FEA.

The reason for these discrepancies is probably that the cracking process in the bond zone predicted by the FEA is different from that in the tests. In reality, small inclined cracks are probably created close to the end surface at low steel stresses, see Fig. 1(a). When the 


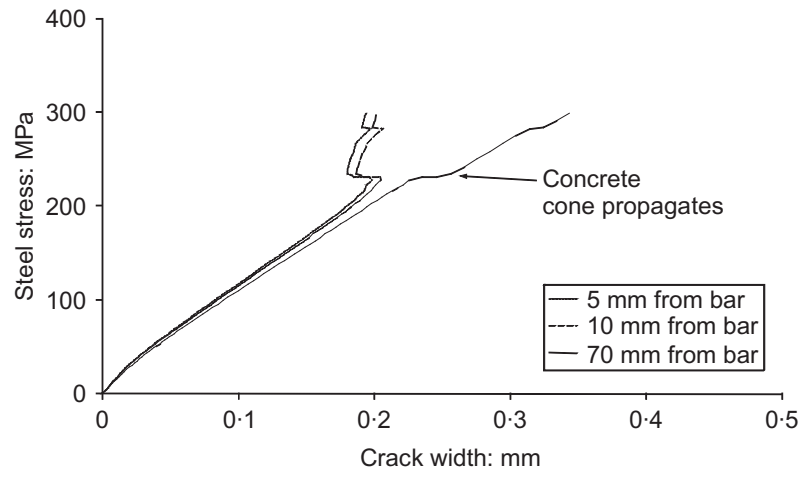

(a)

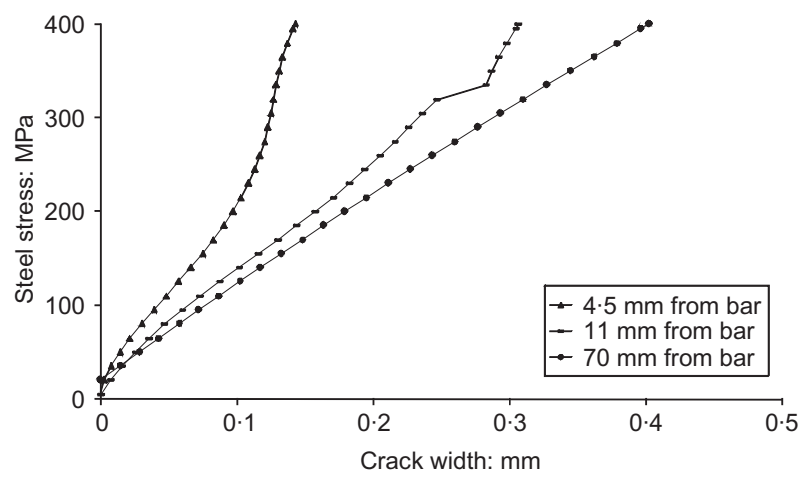

(b)

Fig. 10(a). Calculated crack widths $5 \mathrm{~mm}, 10 \mathrm{~mm}$ and $70 \mathrm{~mm}$ from the reinforcement bar for specimens with $70 \mathrm{~mm}$ concrete cover; (b) crack widths measured $4.5 \mathrm{~mm}, 11 \mathrm{~mm}$ and $70 \mathrm{~mm}$ from the reinforcement bar at specimens with $70 \mathrm{~mm}$ concrete cover

steel stress increases, these early cracks do not grow further as new cracks are created deeper inside the specimen. This implies that the measured crack width at $4.5 \mathrm{~mm}$ is smaller than at $11 \mathrm{~mm}$ from the reinforcement even at low steel stresses. In a later stage some diagonal cracks grow to larger cracks and a coneshaped concrete piece is finally released from the remaining specimen, see Fig. 1(b). The more sudden formation of the concrete cone predicted in the analysis is clearly seen in the results of Figs 9(a) and 10(a). The shape and size of the cone also seems to differ between the tests (Fig. 1(b)) and the calculations in Figs 13 and 14 (see later).

A more detailed model where each rib in the reinforcement is described can be expected to capture the behaviour in an even more detailed way. The inaccuracy of the FEA related to the detailed behaviour in the bond zone can be explained by the modelling of the interaction between the concrete and the reinforcement.

A through-crack develops in the finite-element calculations for the specimen with concrete cover $50 \mathrm{~mm}$ at steel stress $200 \mathrm{MPa}$, see Fig. 2(a). This is shown as an immediate decrease of steel stress in Fig. 9(a). The crack is formed in the middle of the specimens and the crack spacing is reduced to half the original crack spacing $(250 \mathrm{~mm})$. After the formation of a crack at mid-length of the specimen the rate of growth for the cracks becomes significantly smaller. In Fig. 11 test results for the crack width $11 \mathrm{~mm}$ from the reinforcement bar from Tammo and Thelandersson ${ }^{1,2}$ are presented for each individual specimen with concrete cover $50 \mathrm{~mm}$. It is obvious that the crack in the middle forms at the steel stress $200 \mathrm{MPa}$ also in the experiments and the rate of growth for the measured cracks decreases in a similar way.

For ribbed bars, which are exclusively of interest in this study, the crack beahaviour probably is different than for smooth bars. Research of Watstein and Mathey, ${ }^{3}$ however, indicates that the difference in crack widths close to the bar and at the concrete surface is similar for smooth and ribbed bars.

\section{Bond and normal stresses at the interface between concrete and steel}

The crack width is a function of the relative slip between the bar and the concrete crack face and is therefore highly influenced by the bond behaviour near the crack. In Figs 12 and 13 the calculated distributions of bond stress $t_{\mathrm{t}}$ and normal stress $t_{\mathrm{n}}$ (see Fig. 3) along the bar are shown at different levels of steel stress for specimens with $50 \mathrm{~mm}$ cover (Fig. 12) and $70 \mathrm{~mm}$ (Fig. 13). The general behaviour of both specimens is similar except that a crack is formed in the mid-section of the specimen with $50 \mathrm{~mm}$ cover when the steel stress reaches about $200 \mathrm{MPa}$, see also Fig. 9(a). Negative values of $t_{\mathrm{n}}$ correspond to compression and are positive to tension. The zone closest to the end surface is of greatest concern as most of the relative displacement is induced here.

The results in Figs 12 and 13 show that for low stresses, 100 and $200 \mathrm{MPa}$, the distribution of bond stresses and normal stresses is regular and both stresses have a peak close to end of the specimen.

A larger concrete cover increases both the transversal and the longitudinal stiffness, which makes the transfer of stress from steel to concrete more effective. This explains why the concrete cone is created at a somewhat lower steel stress for the specimen with $70 \mathrm{~mm}$

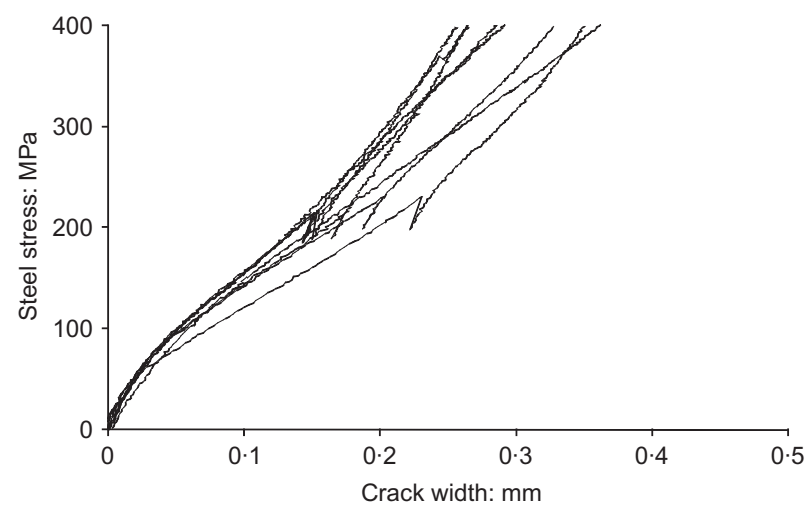

Fig. 11. Measured crack width $11 \mathrm{~mm}$ from the reinforcement bar for specimen with $50 \mathrm{~mm}$ concrete cover. The crack in the middle forms at the steel stress $200 \mathrm{MPa}$ and the rate of the growth for the measured cracks becomes smaller

Magazine of Concrete Research, 2009, 61, No. 1 


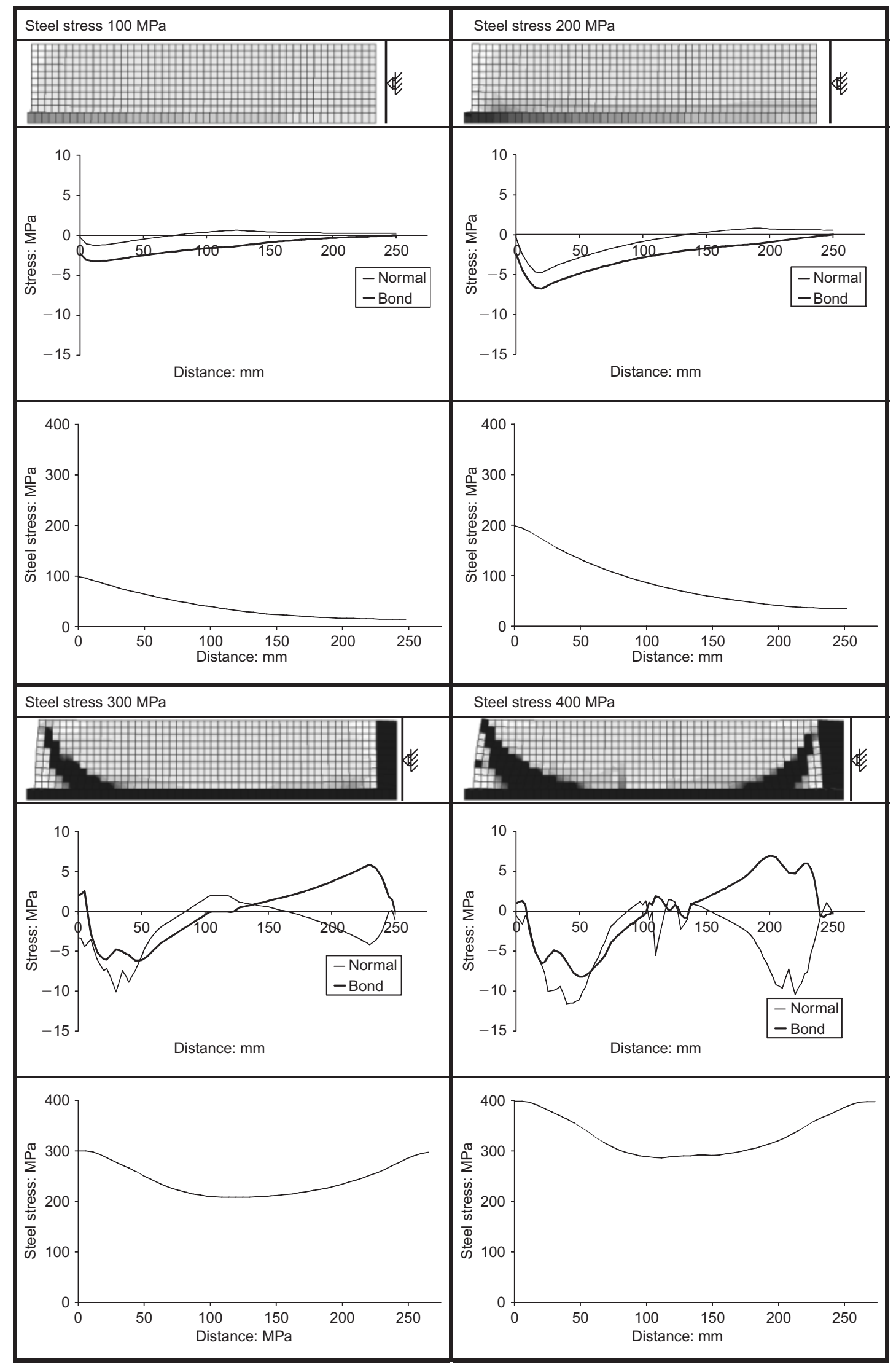

Fig. 12. The left-hand diagrams show the bond stresses and the normal stresses perpendicular to the reinforcement. The righthand diagrams show how the steel stress varies with the distance to the left side of the specimen. The specimen has $50 \mathrm{~mm}$ concrete cover and the steel stresses are 100, 200, 300 and $400 \mathrm{MPa}$. Dark areas represent cracked or softened concrete, with principal tensile strains larger than 0.001 


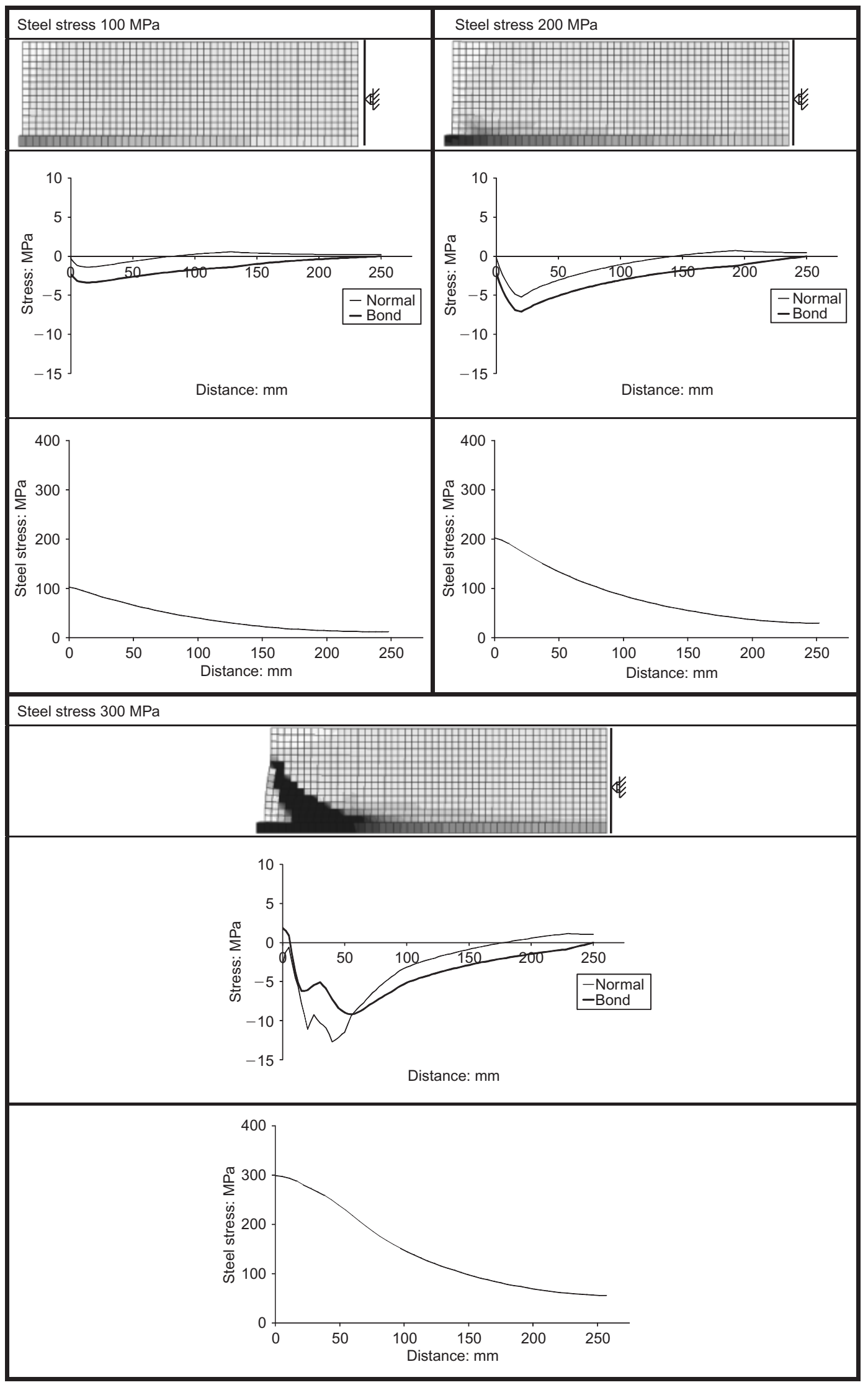

Fig. 13. The left-hand diagrams show the bond stresses and the normal stresses perpendicular to the reinforcement. The righthand diagrams show how the steel stress varies with the distance to the left side of the specimen. The specimen has $70 \mathrm{~mm}$ concrete cover and the steel stresses are 100, 200 and $300 \mathrm{MPa}$. Dark areas represent cracked or softened concrete, with principal tensile strains larger than $0 \cdot 001$. 
cover. For the steel stress $200 \mathrm{MPa}$, the peak bond stress is $7 \cdot 12 \mathrm{MPa}$ for the specimen with $70 \mathrm{~mm}$ cover and $6.75 \mathrm{MPa}$ for the specimen with $50 \mathrm{~mm}$ cover.

The steel stress varies with the distance from the end of the specimen, which is considered here as one of the faces in a crack. In a crack, the entire tensile force is carried by the reinforcement bar. Further into the specimen stresses are transferred to the concrete with a corresponding reduction of steel stress. In the symmetry mid-section $250 \mathrm{~mm}$ from the end the steel stress becomes very low and the concrete carries most of the force until a new crack is created.

As long as the crack spacing is equal, the distribution of bond stress, normal stress and steel stress is more or less independent of concrete cover. For steel stress $300 \mathrm{MPa}$ and higher, the concrete cone has been released by cracking, which has a significant effect on the distribution of bond stresses and normal stresses. Although the simulated cracking process is somewhat different from that observed in the tests, it is believed that the analysis results can give insight into the behaviour at least in a qualitative sense. The formation of the cone implies that the stress peaks will be displaced inwards along the bar, and the bond, as well as normal stress, is strongly reduced near the end.

For the slender specimen (50 mm cover) a crack is formed at mid-section for stresses above $200 \mathrm{MPa}$, see Fig. 12 for steel stresses 300 and $400 \mathrm{MPa}$. This means that the 'crack spacing' is changed from $500 \mathrm{~mm}$ to $250 \mathrm{~mm}$. It is seen that a similar cone is developed near the new crack when the steel stress has reached $400 \mathrm{MPa}$. The behaviour in the two bond zones is not directly correlated with the steel stress level; a higher load is needed to create the concrete cone in the 'new crack' compared to the behaviour at the end of the specimen. As the analysis is nonlinear the response will depend on the loading history, which is different in the two sections.

For steel stresses 300 and $400 \mathrm{MPa}$ a significant cracking and softening takes place in the concrete near the end and near the new crack. In these regions the calculated bond stresses and normal stresses are highly irregular and cannot be considered as fully reliable in a detailed sense owing to possible numerical instability in the analysis.

\section{Distribution of steel stress along the bar}

The total slip and the crack width are strongly related to the mean steel stress of the reinforcement and the crack spacing. From the analysis results in Figs 12 and 13, the mean steel stress is determined over the length between the maximum steel stress ("in the crack') and the minimum steel stress ('between two cracks'). The mean steel stresses are evaluated for the specimens with concrete cover $50 \mathrm{~mm}$ and $70 \mathrm{~mm}$ and different steel stresses $\sigma_{\mathrm{s}}$ in the crack.

One indicator for the capability to transfer the steel stress into the concrete is the ratio between the mean steel stress and the steel stress in the crack. For a given crack spacing, low steel stress ratios indicate effective bond and high capability to transfer steel stresses into the concrete (steel stress ratio 1.0 is equal to no bond). The mean steel stress and the steel stress ratios evaluated from the analysis are given in Table 2.

The results in Table 2 show that the steel stress ratio is almost unaffected by concrete cover for steel stress up to $200 \mathrm{MPa}$. For higher steel stresses, $300 \mathrm{MPa}$ and $400 \mathrm{MPa}$, the formation of a new crack in the middle of the specimen with $50 \mathrm{~mm}$ concrete cover leads to a significantly larger steel stress ratio. This is directly related to the sudden change in crack spacing. As long

Table 2. Mean steel stress and steel stress ratios evaluated from results shown in Figs 12 and 14 and crack widths $w_{s}$ estimated from mean steel stress, equation (6), direct from the FEA and from experiments

\section{Concrete cover $c 50 \mathrm{~mm}$}

\begin{tabular}{l|c|c|c|c|c|c}
\hline $\begin{array}{l}\text { Crack spacing } s_{\mathrm{r}}: \\
\mathrm{mm}\end{array}$ & $\begin{array}{c}\text { Steel stress in crack } \\
\sigma_{\mathrm{s}}: \mathrm{MPa}\end{array}$ & $\begin{array}{c}\text { Mean steel stress } \\
\sigma_{\mathrm{sm}}: \mathrm{MPa}\end{array}$ & $\begin{array}{c}\text { Steel stress } \\
\text { ratio, } v\end{array}$ & $\begin{array}{c}\text { Crack width } w_{\text {sm }} \text { from } \\
\text { mean steel stress: mm }\end{array}$ & $\begin{array}{c}\text { Crack width } w_{\mathrm{sF}} \\
\text { from FEA: mm }\end{array}$ & $\begin{array}{c}\text { Experimental crack } \\
\text { width } w_{\mathrm{sE}}: \text { mm }\end{array}$ \\
\hline 500 & 100 & 40 & $0 \cdot 40$ & $0 \cdot 100$ & $0 \cdot 087$ \\
500 & 200 & 86 & $0 \cdot 43$ & $0 \cdot 215$ & $0 \cdot 190$ \\
250 & 300 & 243 & $0 \cdot 81$ & $0 \cdot 303$ & $0 \cdot 291$ \\
250 & 400 & 337 & $0 \cdot 84$ & $0 \cdot 421$ & $0 \cdot 175$ \\
0
\end{tabular}

Concrete cover $c 70 \mathrm{~mm}$

\begin{tabular}{l|c|c|c|c|c|c}
\hline $\begin{array}{l}\text { Crack spacing } \\
s_{\mathrm{r}}: \mathrm{mm}\end{array}$ & $\begin{array}{c}\text { Steel stress in crack } \\
\sigma_{\mathrm{s}}: \mathrm{MPa}\end{array}$ & $\begin{array}{c}\text { Mean steel stress } \\
\sigma_{\mathrm{sm}}: \mathrm{MPa}\end{array}$ & $\begin{array}{c}\text { Steel stress } \\
\text { ratio, } v\end{array}$ & $\begin{array}{c}\text { Crack width } w_{\text {sm }} \text { from } \\
\text { mean steel stress, } \\
\text { equation (6): mm }\end{array}$ & $\begin{array}{c}\text { Crack width } w_{\text {sF }} \\
\text { from FEA: mm }\end{array}$ & $\begin{array}{c}\text { Experimental crack } \\
\text { width } w_{\mathrm{sE}}: \text { mm }\end{array}$ \\
\hline 500 & 100 & 40 & $0 \cdot 40$ & $0 \cdot 100$ & $0 \cdot 090$ \\
500 & 200 & 84 & $0 \cdot 42$ & $0 \cdot 211$ & $0 \cdot 195$ \\
500 & 300 & 142 & $0 \cdot 47$ & $0 \cdot 355$ & $0 \cdot 346$ \\
500 & 400 & - & - & - & $0 \cdot 288$ \\
\end{tabular}

Magazine of Concrete Research, 2009, 61, No. 1 
as the crack spacing is unchanged, the stress ratio increases only marginally when the steel stress grows.

With knowledge of the mean steel stress and crack spacing, the crack width can be estimated from

$$
w_{\mathrm{sm}}=\frac{\sigma_{\mathrm{sm}} S_{\mathrm{r}}}{E_{\mathrm{s}}}
$$

where $\sigma_{\mathrm{sm}}=v \sigma_{\mathrm{s}}$ is the mean steel stress; $s_{\mathrm{r}}$ is the crack spacing; $E_{\mathrm{S}}$ is the modulus of elasticity of steel $(200 \mathrm{GPa})$; and $v$ is the steel stress ratio.

In Table 2 the crack width $w_{\text {sm }}$ calculated from equation (6) is compared with the crack width at the concrete surface from the FEA and from the experiments, see Figs 9 and 11. The mean steel stress $\sigma_{\text {sm }}$ and the crack spacing are taken from results of the analysis.

The crack width at the concrete surface from the FEA is slightly smaller than the crack width $w_{\text {sm }}$ evaluated from mean steel stress. The reason is that equation (6) does not take the tension of the concrete into account. The results of the comparison in Table 2 indicate, however, that as long as the mean steel stress of the reinforcement is correctly described, the crack width can be estimated with good accuracy even if the tension of the concrete is neglected.

Thus the surface crack width can be seen as a direct function of the product $\sigma_{\mathrm{sm}} s_{\mathrm{r}}=\sigma_{\mathrm{s}} \nu s_{\mathrm{r}}$. At constant crack spacing $s_{\mathrm{r}}$ the steel stress ratio $v$ is a weakly increasing function $v\left(\sigma_{\mathrm{s}}\right)$ of the steel stress $\sigma_{\mathrm{s}}$ in the crack. When new cracks form and the crack spacing $s_{\mathrm{r}}$ changes, the mean steel stress increases strongly together with the steel stress ratio $v$. The effect of decreased crack spacing is directly counteracted by the increased mean steel stress. The influence of the crack spacing on crack width is small, as the product of stress ratio and crack spacing $\left(v s_{\mathrm{r}}\right)$ seems to be independent of crack spacing. The conclusion from this is that the only dominant parameter for estimating surface crack width may be the steel stress $\sigma_{\mathrm{s}}$ in the cracked section. This is reflected in the Gergely and Lutz ${ }^{12}$ equation where the steel stress in the cracked section is the dominating parameter for crack control. The old American Concrete Institute (ACI) code $^{13}$ from 1995 was based on the Gergely and Lutz equation. In 1999 the ACI code switched from the long-held Gergely and Lutz equation and adopted a simplified version of a cracking model developed by Frosh. ${ }^{14}$ The emphasis of the new ACI code ${ }^{15}$ is placed on limiting the reinforcement spacing and not limiting the allowable stress. Another simplification that has attracted a lot of attention is that there is no distinction made between interior and exterior exposure conditions. As the results presented above indicate that the crack width close to the bar mostly depends on the existing steel stress and not so much on concrete cover and bar diameter, the approach in this paper seems strongly to disagree with the new ACI code.

In many codes, as for example Eurocode $2^{16}$ and BBK $04,{ }^{17}$ the crack width calculations are based on crack spacing and mean steel stress, without considering how the crack spacing affects the mean steel stress. By considering the mean steel stress as almost independent of the crack spacing, the latter is conclusive for the crack width. As the crack spacing strongly depends on the concrete cover, these codes generally give a false impression of how the concrete cover affects the crack width. For that reason the codes can be counterproductive with respect to the underlying reason for controlling serviceability. As an example, if small allowable formal crack widths are specified to prevent corrosion in, for example, bridge structures, the codes will lead the engineer to use as small covers as possible or place excessive amounts of reinforcements in sections with high bending moments.

The overestimation of the influence of the concrete cover for crack width calculations and especially the knowledge of the crack behaviour close to the reinforcement bars indicate that the above-mentioned codes should be revised. Perhaps a formula based on the Gergely and Lutz expression ${ }^{12}$ could be used, where the influence of concrete cover is less drastic.

In fact the steel stress alone could be a better and more simple measure to control cracks with respect to durability. Upper limits of steel stress in cracked sections could be set as a function of exposure class. Also for control of cracks, for example with respect to aesthetic qualities, requirements can be described on the basis of limitation of steel stress.

\section{Stresses in the concrete}

For specimens with $50 \mathrm{~mm}$ and $70 \mathrm{~mm}$ concrete cover the stresses in the concrete at different distances from the reinforcement bar and from the free end are presented in Fig. 14. The direction of the concrete stresses is longitudinal and parallel to the reinforcement. The steel stress in the crack is $100 \mathrm{MPa}$.

As close as $2.5 \mathrm{~mm}$ from the left side of the specimens at steel stress $100 \mathrm{MPa}$ the tensile stress in the concrete is zero except a small tensile stress in the zone closest to the bar, see Fig. 14. Further into the structure the tensile stress initially shows more spread $(12.5 \mathrm{~mm}$ and $32.5 \mathrm{~mm}$ ) and then becomes more equally distributed $(102.5 \mathrm{~mm})$. Close to the middle of the specimen, $247.5 \mathrm{~mm}$ from the left side, the tensile stress is more or less uniform for all levels.

The distribution of the concrete stresses for the first $32.5 \mathrm{~mm}$ from the crack is similar for the specimens with both $50 \mathrm{~mm}$ and $70 \mathrm{~mm}$ concrete cover. At larger distances from the crack the smaller specimen forms larger concrete stresses than the larger specimen. The reason for this difference is principally that the force transferred by bond from steel to concrete is distributed over a larger concrete area for the specimen with $70 \mathrm{~mm}$ concrete cover.

A more accurate value of the crack width based on the mean steel stress can be calculated by reducing the total concrete tension from the calculated crack width 


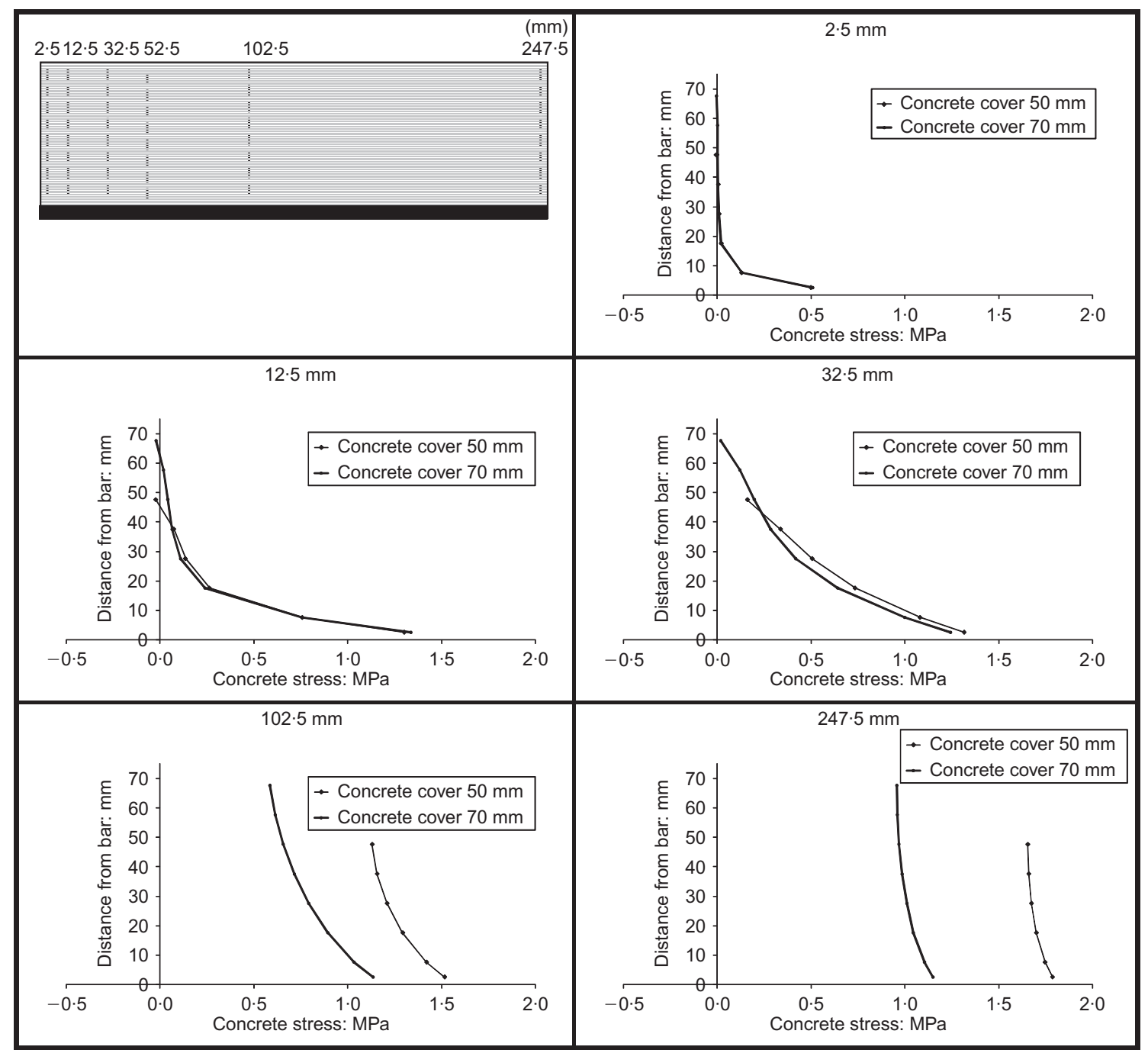

Fig. 14. The diagrams show the longitudinal concrete stresses at different distances from the crack (left concrete surface) and at different levels from the bar surface. The specimens have concrete cover $50 \mathrm{~mm}$ (solid line) and $70 \mathrm{~mm}$ (dotted line). The direction of the concrete stresses is parallel to the bar and the steel stress is $100 \mathrm{MPa}$

$w_{\text {sm }}$ (equation (6)). When the expansion is reduced the crack width from mean steel stress is $0.093 \mathrm{~mm}$ for the specimen with $50 \mathrm{~mm}$ concrete cover and $0.096 \mathrm{~mm}$ for the specimen with $70 \mathrm{~mm}$ concrete cover for steel stress $100 \mathrm{MPa}$ and $0.301 \mathrm{~mm}$ and $0.347 \mathrm{~mm}$ for steel stress $300 \mathrm{MPa}$. These crack widths are very similar to the crack width from the FEA $w_{\mathrm{sF}}$ in Table 2, which interprets that the concrete expansion does affect the crack width to some extent. However, it is very uncertain if this expansion is of any interest for practical use.

\section{Conclusions}

(a) FEM is a suitable tool to gain a better insight into the nonlinear mechanisms that affect the crack width close to the reinforcement.

(b) The results of the analysis verify the statement that the effect of concrete cover on the crack widths close to the reinforcement bar is limited. (c) The analyses confirm that the formation of a concrete cone around the reinforcement bar is of great importance for the mechanism of cracking and the width of crack.

(d) The dominant parameter for estimating the corrosion risk may be the steel stress in the cracked section.

(e) Upper limits of steel stress in cracked sections could be set as a function of exposure class.

\section{References}

1. Tammo K. and Thelandersson S. Crack opening near reinforcement bars in concrete structures. Structural Concrete, Journal of the fib, 2006, 7, No. 4, 137-142.

2. TAMmo K. and Thelandersson S. Crack behaviour near reinforcement bars in concrete structures. ACI Structural Journal, accepted for publication.

3. Watstein D. and Mathey R. Width of cracks in concrete at the surface of reinforcing steel evaluated by means of tensile 
bond specimens. Journal of the American Concrete Institute, 1959, 56, No. 7, 47-56.

4. Broms B. Theory of the calculation of crack width and crack spacing in reinforced concrete members. Cement och Betong, 1968, No. 1, 52-64. In Swedish.

5. YanNOPOULUS P. J. Variation of concrete crack widths through the concrete cover to reinforcement. Magazine of Concrete Research, 1989, 41, No. 147, 63-68.

6. Beeby A. W. The influence of the parameter $\varphi / \rho_{\text {eff }}$ on crack widths. Structural Concrete, 2004, 5, No. 2, 71-83.

7. TNO. DIANA Finite Element Analysis, User's Manual Release 8.1. TNO Building and Construction Research, Delft, The Netherlands, 2002.

8. Thornfeldt E., Tomaszewic A. and Jensen J. J. Mechanical properties of high-strength concrete and application in design. Proceedings of the Utilization of High Strength Concrete Symposium, Stavanger, Norway, 1987.

9. Hordisk D. A. Local Approach to Fatigue of Concrete. PhD thesis, Delft University of Technology, Delft, The Netherlands, 1991.

10. Cornelissen H. A. W., Hordijk D. A. and Reinhardt H. W. Experimental determination of crack softening characteristics of normal weight and lightweight concrete. Heron, 1986, 31, No. $2,45-56$.

11. Lundgren K. Bond between ribbed bars and concrete. Part 1: modified model. Magazine of Concrete Research, 2005, 57, No. 7, 371-382.

12. Gergely P. and Lutz L. A. Maximum crack width in reinforced concrete flexural members. Causes, Mechanism, and Control of Cracking in Concrete, SP-20. American Concrete Institute, Detroit, 1968, pp. 87-117.

13. American Concrete Institute. ACI 318-95, Building Code Requirements for Reinforced Concrete (ACI 318-95) and Commentary (ACI 318R-95). ACI, Detroit, Michigan, 1995.

14. Frosh R. J. Flexural Crack Control in Reinforced Concrete, Design and Construction Practices to Mitigate Cracking. SP 204. ACI, Farmington Hills, Michigan, 2001, pp. 135-154.

15. American Concrete Institute. ACI 318-99. Building Code Requirements for Structural Concrete (ACI 318-99) and Commentary (ACI 318R-99). ACI, Farmington Hills, Michigan, 1999.

16. Comité Européen du Béton. EN 1992-1-1: Design of Concrete Structures. Part 1: General Rules and Rules for Buildings. CEN, Brussels, 2005.

17. BBK. Boverkets handbok om betongkonstruktioner, BBK04. Boverket, Karlskrona, Sweden, 2004.

Discussion contributions on this paper should reach the editor by 1 August 2009 